\title{
Os efeitos das diferentes formas de capital no desempenho escolar: um estudo à luz de Bourdieu e de Coleman
}

\author{
Alicia Bonamino, Fátima Alves, Creso Franco \\ Departamento de Educação da Pontifícia Universidade Católica do Rio de Janeiro
}

Sibele Cazelli

Coordenação de Educação do Museu de Astronomia (MAST)

\section{Introdução}

No transcorrer da primeira metade do século XX, a visão predominante atribuía à escolarização papel central na construção de uma nova sociedade, justa, aberta e democrática, na qual o acesso à escola pública e gratuita garantiria a igualdade de oportunidades. Segundo essa visão, os "indivíduos competiriam dentro do sistema de ensino, em condições iguais, e aqueles que se destacassem por seus dons individuais seriam levados, por uma questão de justiça, a avançar em suas carreiras escolares e, posteriormente, a ocupar as posições superiores na hierarquia social" (Nogueira \& Nogueira, 2002, p. 16).

Foi, entretanto, no contexto da democratização do acesso à escola e do prolongamento da escolaridade obrigatória que se tornou evidente o problema das desigualdades de escolarização entre os grupos sociais. O otimismo marcante do período anterior foi substituído por uma postura mais pessimista, embasada pela divulgação de uma série de surveys educacionais que mostravam a influência da origem social nos resultados escolares. O Relatório Coleman ${ }^{1}$ (1966) constitui um marco na ruptura com a visão otimista de construção de uma sociedade igualitária pela via da educação para todos.

Além disso, as inúmeras frustrações com o caráter autoritário e elitista do sistema educacional e com o baixo retorno econômico e social decorrente da posse de diplomas de determinados cursos tornaram "imperativo reconhecer que o desempenho escolar não dependia, tão simplesmente, dos dons individuais, mas da origem social dos alunos" (Coleman, 1966, p. 16).

Em particular, os estudos de Bourdieu acentuaram que a origem social dos alunos leva às desigualdades escolares e, mais ainda, que as desigualdades escola-

\footnotetext{
${ }^{1}$ Esse estudo, encomendado pelo Act of Civil Rights de 1964,
} foi inovador por uma série de razões. Primeiramente, reuniu informações de mais de meio milhão de estudantes, contendo dados não somente dos alunos e de suas escolas, como também do desempenho escolar de cada um. Em segundo lugar, abordou a relação entre insumos escolares e o desempenho dos estudantes. 
res reproduzem o sistema objetivo de posições e de dominação.

Bourdieu e Coleman introduziram o conceito de capital na análise social para referir-se não apenas à sua forma econômica mas também à sua forma cultural e social. O termo da área econômica "capital” foi utilizado por esses sociólogos no estudo das desigualdades escolares como referência das vantagens culturais e sociais que indivíduos ou famílias mobilizam e, via de regra, os conduzem a um nível socioeconômico mais elevado.

A problemática que leva Bourdieu e Coleman a uma concepção ampliada do conceito de capital repousa fundamentalmente sobre evidências empíricas que apontam as limitações do conceito de capital econômico para explicar plenamente a relação entre origem socioeconômica e resultados educacionais, levando esses sociólogos a considerar que outras formas de capital, tais como o capital social e o cultural, contribuem e interagem diretamente com o capital econômico para fortalecer essa relação.

Embora desenvolvam o conceito de capital em bases teóricas distintas, Bourdieu e Coleman compartilham concepções similares, particularmente no que se refere ao conceito de capital econômico.

O presente estudo tem como objetivos avaliar os méritos relativos dessas duas concepções sociológicas dos conceitos de capital; explorar o potencial explicativo dos capitais econômico, social e cultural na análise do desempenho educacional; e analisar os efeitos das diferentes formas de capital, bem como sua mobilização no contexto familiar sobre o desempenho em leitura dos estudantes brasileiros participantes do Programa Internacional de Avaliação de Alunos (PISA 2000).

Nossa hipótese é que determinados arranjos de capitais possuem efeitos diferenciados sobre o desempenho escolar dos alunos e que isso se relaciona com o grau de mobilização da rede de apoio familiar.

\section{Capitais: diferentes concepções e suas dimensões}

Nas próximas seções, desenvolveremos os pontos que parecem mais pertinentes para a compreensão dos conceitos de capital econômico, social e cultural de Bourdieu e Coleman, em uma perspectiva que enfatiza as comunalidades e diferenças entre esses dois sociólogos.

\section{Capital econômico}

Bourdieu (1989) vê o espaço social como um campo de lutas onde os agentes (indivíduos e grupos) elaboram estratégias que permitem manter ou melhorar sua posição social. Essas estratégias estão relacionadas com os diferentes tipos de capital.

O capital econômico, na forma de diferentes fatores de produção (terras, fábricas, trabalho) e do conjunto de bens econômicos (dinheiro, patrimônio, bens materiais), é acumulado, reproduzido e ampliado por meio de estratégias específicas de investimento econômico e de outras relacionadas a investimentos culturais e à obtenção ou manutenção de relações sociais que podem possibilitar o estabelecimento de vínculos economicamente úteis a curto e longo prazo.

Para esse sociólogo, a educação escolar, uma das formas do capital cultural, é um recurso tão útil quanto o capital econômico na determinação e reprodução das posições sociais. Principalmente nas pesquisas conduzidas em conjunto com Passeron (1964, 1970), Bourdieu desvenda a seletividade educacional que elimina e marginaliza os alunos oriundos das classes populares, enquanto privilegia os alunos mais dotados de capital econômico, cultural e social, contribuindo assim para a reprodução, de geração em geração, dos capitais acumulados. Essa teoria contraria a convicção, até então amplamente aceita, de que existe igualdade de chances no sistema educacional.

Por sua vez, Coleman (1988) define o capital econômico como renda e riqueza material e também em termos dos bens e serviços a que ele dá acesso. Esse autor vê o capital econômico como uma parte importante da relação que une a origem familiar às diferentes posições socioeconômicas. Portanto, como um dos fatores relacionados ao contexto familiar que influenciam o desenvolvimento da criança. Nesse sentido, é plausível esperar que famílias que têm capital econômico elevado proporcionem a seus filhos acesso 
a excelentes instituições de ensino, a bens culturais variados de alta qualidade e a viagens de estudo. Além de cuidados cotidianos, baseados na presença permanente de um dos pais durante os anos de formação e de escolarização dos filhos, e de um local apropriado para o estudo dentro de casa.

Em síntese, a definição de capital econômico utilizada por Coleman é basicamente idêntica àquela utilizada por Bourdieu, ainda que o sociólogo francês enfatize os conflitos e a competição dos indivíduos e grupos por posições nos diferentes campos sociais. Mais adiante, veremos que esses dois autores concebem diferenciadamente a articulação entre esta e as outras formas de capital.

\section{Capital Social}

Na década de 1980, os sociólogos Bourdieu e Coleman transformaram o capital social em um tópico específico de estudo para tentar entender como indivíduos inseridos em uma rede estável de relações sociais podem beneficiar-se de sua posição ou gerar externalidades positivas para outros membros.

Em particular, o papel das famílias na construção do capital social tem sido abordado pela literatura por dois ângulos. O primeiro examina a construção do capital social no interior das redes familiares e a importância disso para o desenvolvimento escolar e cognitivo dos filhos. $\mathrm{O}$ segundo ângulo focaliza o papel das famílias na construção de capital social extrafamiliar, ou seja, em redes fora do lar e no interior de contextos econômicos, estatais e/ou comunitários, formais e informais. Este último enfoque é dominante na literatura atual sobre capital social (Putnam, 1993; Kliksberg, 2000).

$\mathrm{Na}$ concepção de capital social sustentada por Bourdieu (1980), destacam-se três aspectos: os elementos constitutivos; os benefícios obtidos pelos indivíduos mediante sua participação em grupos ou redes sociais e as formas de reprodução desse tipo de capital.

Os dois elementos que constituem o capital social são as redes de relações sociais, que permitem aos indivíduos ter acesso aos recursos dos membros do grupo ou da rede; e a quantidade e a qualidade de recursos do grupo.

Em relação ao primeiro elemento, Bourdieu (1980, p. 67) define o capital social como a agregação de recursos atuais ou potenciais que tem ligação estreita com uma rede durável de relações institucionalizadas de reconhecimento e de inter-reconhecimento. As relações estabelecidas entre os indivíduos pertencentes a um determinado grupo não advêm apenas do compartilhamento de relações objetivas ou de proximidade no mesmo espaço econômico e social. Essas relações fundam-se também nas trocas materiais e simbólicas, cuja instauração e perpetuação supõem o reconhecimento dessa proximidade pelos agentes. Dito de outra forma, essas redes sociais (família, clube, escola etc.) dão ao indivíduo o sentimento de pertencimento a um determinado grupo.

$\mathrm{O}$ segundo elemento diz respeito à quantidade $\mathrm{e}$ à qualidade de recursos do grupo. De acordo com esse autor, o volume de capital social de um agente individual depende tanto da extensão da rede de relações que ele pode efetivamente mobilizar como do volume das diferentes formas de capital (econômico, cultural ou simbólico) que é propriedade exclusiva de cada um dos agentes a quem o indivíduo está ligado.

Embora o capital econômico seja a fonte de todas as outras formas de capital, Bourdieu deixa claro que o capital social tende a ser transformado em capital econômico ou em capital cultural.

Em relação aos ganhos obtidos pelos indivíduos em decorrência de sua participação nos grupos, Bourdieu ressalta que essa participação permite a apropriação dos benefícios materiais e simbólicos que circulam entre os membros da rede.

Diretamente relacionada a essa apropriação está, em terceiro lugar, a reprodução do capital social, que é produto do trabalho necessário para produzir as redes de relações duráveis que podem proporcionar os benefícios materiais e simbólicos que circulam entre seus membros.

Nessa perspectiva, destaca-se a importância do capital social para as diversas frações de classe. A participação em determinados grupos ou redes sociais 
abre oportunidades de aumentar o rendimento do capital social e dos investimentos escolares, na forma de benefícios simbólicos (status ocupacional, por exemplo) ou na forma de benefícios salariais.

Bourdieu relaciona o capital social aos benefícios mediados pelas redes extrafamiliares e às lutas concorrenciais entre indivíduos ou grupos no interior de diferentes campos sociais. Para ele, as chances que os agentes têm de acumular ou de reproduzir capital social dependem de sua posição dentro do sistema de estratificação (Ortiz, 1983).

O conceito de capital social em Bourdieu é solidário com suas formulações sobre disposições duráveis (habitus). O habitus enfatiza a dimensão de um aprendizado passado que tende a conformar e a orientar as ações dos agentes. É o sistema de esquemas para a elaboração de práticas concretas, ou esquemas estruturados, incorporados pelos agentes na forma de um senso prático que facilita sua orientação nos domínios relativos à existência social. A interiorização, pelos agentes, de valores, normas e princípios sociais assegura a adequação entre as ações do sujeito e a realidade objetiva da sociedade como um todo.

Tem-se aqui uma crítica à teoria da ação racional. $\mathrm{Na}$ base dessa concepção sobre a relação do agente com a mobilização do capital social está uma teoria não intelectualista da ação. Bourdieu (1997, p. 50) lembra que é necessário deixar de lado tanto o mecanicismo, que considera a ação como resultado de constrangimentos de causas externas, como o finalismo, em particular a teoria da ação racional, que sustenta que $\mathrm{o}$ agente atua de maneira livre e consciente. $\mathrm{O}$ autor afirma que é necessário passar a conceber a ação como produto de um cálculo prático de possibilidades e benefícios, guiada por uma razão prática, que é a lógica do senso prático, "uma lógica em ação", que permite ao agente "agir quando é necessário" e lhe possibilita um conhecimento prático do mundo social.

Por sua vez, Coleman (1988, p. 98) define o capital social pela sua função, considerando-o uma variedade de diferentes entidades que compartilham aspectos das estruturas sociais facilitadoras de certas ações dos atores (pessoas ou grupos). Como as ou- tras formas de capital, o capital social é produtivo, permitindo a realização de certos fins que, na sua ausência, não seriam possíveis. Da mesma forma que o capital físico e o capital humano, o capital social não é completamente conversível em capital econômico, mas pode ser especialmente importante para certas atividades. Essa importância é de natureza variável, podendo uma determinada forma de capital social ser valiosa, no sentido de facilitar certas ações, inútil ou mesmo prejudicial, para outras.

Esse autor argumenta que o capital social não é um atributo dos indivíduos, mas um aspecto dependente do contexto e da estrutura social, ou seja, inerente à estrutura das relações entre dois ou vários atores. Isso quer dizer que o capital social não está alojado nem nos próprios atores nem nos instrumentos físicos de produção: só acontece nas relações entre as pessoas e por meio de trocas que facilitam a ação de indivíduos ou grupos. Associa o valor do capital social aos aspectos da estrutura social que atuam como recursos utilizados pelos atores "para alcançar seus interesses" (idem, p. 110).

Nessa perspectiva, ele especifica três aspectos da estrutura social: (i) as obrigações, as expectativas e a confiabilidade das estruturas; (ii) os canais de informação; e (iii) as normas e sanções efetivas. Tais aspectos influenciam a qualidade das relações formadas nos grupos sociais, facilitando especialmente o engajamento das pessoas na troca de recursos, na assistência mútua e na demonstração de empatia com os interesses dos outros.

O sociólogo americano destaca o aspecto funcional do capital social e constrói uma explicação sobre fontes, mecanismos e resultados da formação desse tipo de capital referenciada no aspecto relacional da estrutura social. A explicação sobre como esses recursos são acessados, acumulados e postos para funcionar está baseada em aspectos valorativos inerentes aos grupos ou redes sociais, tais como as expectativas de reciprocidade entre seus membros, a execução das normas no grupo, a "clausura" ou fechamento das redes sociais e a adequação da organização social (Hogan \& Owen, 2000). 
Coleman (1988) procurou desenvolver uma teoria sociológica que inclui aspectos de tradições intelectuais da economia, mais especificamente da teoria da ação racional, e da sociologia, especialmente da teoria da estrutura social. Ele aceita o princípio da ação racional e tenta mostrar como esse princípio, em conjunção com contextos sociais particulares, pode ser responsável não somente pelas ações dos indivíduos nas redes sociais privadas mas também pelo desenvolvimento da organização social. Seu objetivo original era importar o princípio econômico da ação racional para a análise dos próprios sistemas sociais, incluindo o sistema econômico sem, entretanto, limitar-se a ele ou descartar a organização social (Coleman, 1988, p. 97). Essa perspectiva comporta uma versão crítica às acepções radicalmente individualistas da teoria da ação racional.

Em síntese, enquanto Bourdieu enfatiza os conflitos e as lutas concorrenciais entre indivíduos e grupos pelos diferentes espaços de poder, Coleman destaca os meios pelos quais os diferentes grupos sociais trabalham em conjunto e as relações de reciprocidade e de confiança estabelecidas entre seus membros. Provavelmente, as diferenças existentes entre essas duas perspectivas contêm, de maneira implícita, parte das razões que tanto levam Bourdieu a relativizar o papel da família na mobilização de capital social como levam Coleman a enfatizar as relações internas à família como uma das principais fontes de mobilização desse tipo de capital.

Capital social baseado na família

Coleman compartilha a perspectiva que aborda o papel das famílias na construção de capital social por dois ângulos. O primeiro focaliza o papel das famílias na construção de capital social extrafamiliar, ou seja, em redes sociais fora do lar. O segundo ângulo examina a construção do capital social no interior das redes familiares e a importância disso para o desenvolvimento individual de seus membros, especialmente para o desempenho escolar e cognitivo dos filhos. A segunda abordagem lança luz sobre os contextos tipicamente privados, informais, intensos e duráveis das relações familiares, nos quais acontecem as interações face a face.

Em particular, Coleman (idem, p. 110) examina os aspectos da vida familiar que parecem cruciais para o capital social. Mostra a importância do capital social dentro da família para a educação dos filhos.

A presença do capital social é considerada vital para transferir o capital humano dos pais para os filhos: "se o capital humano possuído pelos pais não é complementado pelo capital social enraizado nas relações familiares, o capital humano dos pais torna-se irrelevante para o crescimento educacional dos filhos" (idem, p. 111).

O exemplo a seguir ilustra o que é e como opera o capital social baseado na família. Segundo o sociólogo, investigações realizadas em um distrito educacional norte-americano revelaram que famílias asiáticas compravam livros didáticos em duplicata, destinando um deles ao aprendizado das mães, com o propósito de apoiar melhor a escolarização dos filhos. Esse é um caso em que "o capital humano dos pais, ao menos quando medido tradicionalmente como número de anos de escolaridade, é baixo, mas o capital social disponível na família para a educação dos filhos é extremamente alto" (idem, p. 110).

Esse exemplo ilustra dois aspectos interessantes. O primeiro é que os filhos são afetados pelo capital humano dos pais; entretanto, se esse capital não for complementado pelo capital social incorporado nas relações familiares, pode ser irrisório para o crescimento educacional dos filhos. O segundo aspecto relevante está associado ao fato de que, para Coleman, o capital social não pode ser entendido apenas como o apoio recebido, uma vez que mobilizar a rede de apoio social é parte integrante desse conceito. No exemplo mencionado, as famílias asiáticas eram consideradas portadoras de capital social "extremamente alto", porque o movimento para adquirir material didático suplementar mostra exatamente a mobilização da rede de apoio social.

Capital cultural em Bourdieu

Para Bourdieu (1979), a noção de capital cultural surge da necessidade de compreender as desigualdades 
de desempenho escolar dos indivíduos oriundos de diferentes grupos sociais.

Sua sociologia da educação caracteriza-se notadamente pela diminuição do peso do fator econômico, em comparação com o peso do fator cultural na explicação das desigualdades escolares.

O capital cultural pode existir em três estados: incorporado, objetivado e institucionalizado, e sua acumulação inicial "começa desde a origem, sem atraso, sem perda de tempo, pelos membros das famílias dotadas de um forte capital cultural" (Bourdieu, 1979, p. 76).

No estado incorporado, dá-se na forma de disposições duráveis do organismo, tendo como principais elementos constitutivos os gostos, o domínio maior ou menor da língua culta e as informações sobre o mundo escolar. A acumulação dessa forma de capital cultural demanda que sua incorporação seja feita mediante um trabalho de inculcação e assimilação. A internalização exige investimentos de longa duração para tornar essa forma de capital parte integrante da pessoa (habitus). Esse trabalho deve ser realizado pessoalmente pelo agente; "não pode ser transmitido instantaneamente [...] por doação ou transmissão hereditária, por compra ou troca. Pode ser adquirido, de maneira totalmente dissimulada e inconsciente, e permanece marcado por suas condições primitivas de aquisição" (idem, p. 75).

O capital cultural, no seu estado incorporado, constitui o componente do contexto familiar que atua de forma mais marcante na definição do futuro escolar da prole, uma vez que as referências culturais, os conhecimentos considerados apropriados e legítimos e o domínio maior ou menor da língua culta trazida de casa (herança familiar) facilitam o aprendizado dos conteúdos e dos códigos escolares, funcionando como uma ponte entre o mundo da família e o da escola.

No estado objetivado, o capital cultural existe na forma de bens culturais, tais como esculturas, pinturas, livros etc. Para possuir os bens econômicos na sua materialidade, é necessário ter simplesmente capital econômico, o que se evidencia na compra de livros, por exemplo. Todavia, para apropriar-se simbolicamente desses bens é necessário possuir os instrumentos dessa apropriação e os códigos necessários para decifrá-los, ou seja, é necessário possuir capital cultural no estado incorporado.

Por último, o capital cultural institucionalizado ocorre basicamente na forma de títulos escolares. O grau de investimento na carreira escolar está vinculado ao retorno provável que se pode obter com o título escolar, notadamente no mercado de trabalho. Esse retorno - ou seja, o valor do título escolar - pode ser alto ou baixo; quanto mais fácil o acesso a um título escolar, maior a tendência à sua desvalorização. É o que Bourdieu chama de "inflação de títulos".

Coleman e o conceito de capital humano

Esse sociólogo considera que o capital humano é medido aproximadamente pelo nível de instrução das pessoas. No caso das famílias, o capital humano, medido pela instrução dos pais, é potencialmente importante para proporcionar um ambiente cognitivo propício à aprendizagem escolar da criança.

Assim como o capital econômico, no qual as pessoas investem para auferir os benefícios que ele produz, para construir e acumular capital humano, a pessoa também precisa investir recursos e tempo na educação escolar, de modo que colha seus benefícios, seja na forma de um emprego mais bem remunerado, seja para obter uma maior satisfação no trabalho, seja para atingir um status mais alto ou pelo simples prazer de adquirir um entendimento maior do mundo circundante.

Em síntese, a definição de Coleman de capital humano guarda comunalidades com a definição de capital cultural institucionalizado de Bourdieu. Em função do recorte do presente artigo, o conceito de capital humano desenvolvido por Coleman tem relevância relativamente pequena. Contrariamente, o conceito de capital cultural elaborado por Bourdieu é mais amplo e complexo, tendo maior centralidade neste estudo, na medida em que destaca a influência dos três estados do capital cultural no desempenho dos indivíduos no sistema escolar. 


\section{Metodologia}

Dados

Para a realização desta investigação, foram utilizados os dados do Brasil no PISA 2000. No PISA, uma amostra de jovens de 15 anos matriculados em escolas foi submetida a testes nas áreas de leitura, matemática e ciências. A população de referência do PISA é composta por jovens que frequentam a escola, com idade entre 15 anos e 3 meses e 16 anos e 3 meses. No caso brasileiro, essa população encontra-se espalhada em diversas séries, existindo uma concentração na $7^{\mathrm{a}} \mathrm{e} 8^{\mathrm{a}}$ séries do ensino fundamental e no $1^{\circ} \mathrm{e} 2^{\circ}$ anos do ensino médio. Essas foram as séries consideradas no processo de amostragem do PISA/Brasil. Foram excluídos da população de referência os estudantes das escolas rurais da Região Norte e das escolas rurais com menos de cinco alunos matriculados. Uma amostra probabilística complexa, envolvendo estratificação e conglomerados, foi obtida via sorteio de escolas e, dentro delas, dos alunos nas idades e nas séries incluídas na população de referência. No Brasil, a amostra dessa avaliação internacional envolveu 4.893 estudantes.

O PISA é elaborado por um consórcio de instituições, liderado pelo Australian Council for Educational Research, no âmbito do programa de educação da Organização para a Cooperação e o Desenvolvimento Econômico (OCDE). O principal objetivo do PISA é aferir até que ponto os alunos próximos do final da educação obrigatória adquiriram conhecimentos e habilidades necessárias para uma participação plena e efetiva na sociedade.

A primeira avaliação ocorreu em 2000 e contou com a participação de 32 países e mais de 200 mil estudantes. Um novo exercício de avaliação ocorreu em 2003 (dados não divulgados até o momento da elaboração deste artigo) e está prevista outra avaliação para 2006. Cabe ressaltar que, em cada avaliação, uma das áreas de conhecimento é explorada em profundidade. Em 2000, a área de leitura foi privilegiada (dois terços do teste destinam-se a um determinado domínio); nas próximas avaliações serão matemática e ciências, respectivamente.
Essa avaliação internacional caracteriza-se por focalizar não somente os conhecimentos e habilidades dos estudantes mas também seus hábitos de estudo, motivações e preferências. Utiliza, além dos testes cognitivos, questionários que levantam informações de natureza sociodemográfica e cultural. No PISA, o conceito de letramento adquire um papel central na avaliação do desempenho dos estudantes, indo além da simples habilidade de ler e escrever. O letramento, em leitura, matemática ou ciências, diz respeito aos conhecimentos e habilidades requeridos para uma atuação efetiva na sociedade, cuja aquisição ocorre ao longo da vida, não se restringindo ao período escolar. Situações de interação com os pares, colegas, comunidade em geral e diversos espaços de caráter cultural também são consideradas essenciais para a promoção do letramento dos indivíduos.

\section{Medidas utilizadas}

O quadro 1 e a tabela 1 apresentam a definição e a estatística descritiva das variáveis usadas nos modelos estimados. Outras variáveis foram consideradas nas análises; entretanto, diante dos resultados obtidos, não foram incluídas no modelo aqui apresentado. Em função dos nossos objetivos, classificamos as variáveis explicativas levando em conta três os tipos de capital: econômico, social e cultural.

\section{Abordagem analítica}

A análise dos dados foi realizada por meio de modelos de regressão linear, uma vez que um dos objetivos deste trabalho é investigar os efeitos das diferentes formas de capital (econômico, cultural, social) das famílias sobre o desempenho em leitura dos estudantes brasileiros. O presente estudo não ignora o papel dos fatores escolares no desempenho dos alunos, mas está especificamente voltado para a investigação da incidência do apoio familiar na produção de condições favoráveis para a melhoria do desempenho escolar.

Nas seções anteriores, mostramos que os estudos de Coleman enfatizam as relações internas à família como uma das principais fontes de mobilização do 
Quadro 1 - Descrição das Variáveis Utilizadas

\begin{tabular}{|c|c|c|c|}
\hline $\begin{array}{l}\text { Tipo de } \\
\text { capital }\end{array}$ & Variável & Tipo e codificação & Descrição \\
\hline & Proficiência & Contínua & Proficiência em leitura \\
\hline 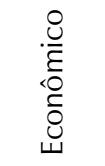 & Posse de bens & Contínua & $\begin{array}{l}\text { Medida sobre a posse de bens, obtida a partir de respostas dos alunos ao } \\
\text { questionário. Valores positivos indicam maior posse de bens e valores negativos } \\
\text { indicam baixa posse de bens nas casas dos alunos (Original do PISA-WEALTH). }\end{array}$ \\
\hline \multirow{7}{*}{$\overline{\frac{\pi}{U}}$} & $\begin{array}{l}\text { Diálogo } \\
\text { familiar }\end{array}$ & Contínua & $\begin{array}{l}\text { Medida do diálogo familiar sobre diversos assuntos. Obtida por TRI não } \\
\text { paramétrica a partir de itens do questionário do aluno. }\end{array}$ \\
\hline & $\begin{array}{l}\text { Status } \\
\text { ocupacional }\end{array}$ & Contínua & $\begin{array}{l}\text { Medida sobre o status ocupacional dos pais dos alunos, obtida a partir da } \\
\text { classificação das ocupações dentro do Internacional Standard Classification of } \\
\text { Occupations (Original do PISA-ISEI). }\end{array}$ \\
\hline & $\begin{array}{l}\text { Recursos } \\
\text { educacionais } \\
\text { familiares }\end{array}$ & Contínua & $\begin{array}{l}\text { Medida sobre a disponibilidade e a quantidade de recursos educacionais em } \\
\text { casa, obtida a partir das respostas dos alunos. Valores positivos indicam maior } \\
\text { disponibilidade de recursos e valores negativos indicam menor disponibilidade } \\
\text { desses recursos pelas famílias. (Original do PISA- HEDRES). }\end{array}$ \\
\hline & $\begin{array}{l}\text { Baixa posse - } \\
\text { baixo recurso }\end{array}$ & $\begin{array}{c}\text { Dicotômica } \\
(1=\operatorname{sim} / 0=\text { não })\end{array}$ & $\begin{array}{l}\text { Dummy que indica o pertencimento ao conglomerado que se caracteriza por } \\
\text { baixos valores de posse de bens e baixos valores de recursos educacionais } \\
\text { familiares (obtida via análise de conglomerado). }\end{array}$ \\
\hline & $\begin{array}{l}\text { Alta posse - } \\
\text { alto recurso }\end{array}$ & $\begin{array}{l}\text { Dicotômica } \\
(1=\operatorname{sim} / 0=\text { não })\end{array}$ & $\begin{array}{l}\text { Dummy que indica o pertencimento ao conglomerado que se caracteriza por } \\
\text { altos valores de posse de bens e altos valores de recursos educacionais familiares } \\
\text { (obtida via análise de conglomerado). }\end{array}$ \\
\hline & $\begin{array}{l}\text { Alta posse - } \\
\text { baixo recurso }\end{array}$ & $\begin{array}{l}\text { Dicotômica } \\
(1=\operatorname{sim} / 0=\text { não })\end{array}$ & $\begin{array}{l}\text { Dummy que indica o pertencimento ao conglomerado que se caracteriza } \\
\text { por altos valores de posse de bens e baixos valores de recursos educacionais } \\
\text { familiares (obtida via análise de conglomerado). }\end{array}$ \\
\hline & $\begin{array}{l}\text { Baixa posse - } \\
\text { alto recurso }\end{array}$ & $\begin{array}{l}\text { Dicotômica } \\
(1=\operatorname{sim} / 0=\text { não })\end{array}$ & $\begin{array}{l}\text { Dummy que indica o pertencimento ao conglomerado que se caracteriza } \\
\text { por baixos valores de posse de bens e altos valores de recursos educacionais } \\
\text { familiares (obtida via análise de conglomerado). }\end{array}$ \\
\hline \multirow{2}{*}{$\frac{\overline{\frac{\pi}{2}}}{\frac{1}{3}}$} & $\begin{array}{l}\text { Posse de bens } \\
\text { culturais }\end{array}$ & Contínua & $\begin{array}{l}\text { Medida sobre a posse de bens relacionados à cultura clássica, obtida a partir das } \\
\text { respostas dos alunos ao questionário. Valores positivos indicam alta posse de } \\
\text { bens culturais e valores negativos indicam baixa posse de bens culturais na casa } \\
\text { do aluno (Original do PISA-CULTPOSS). }\end{array}$ \\
\hline & $\begin{array}{l}\text { Nível de } \\
\text { escolaridade } \\
\text { da mãe }\end{array}$ & Contínua & $\begin{array}{l}\text { Medida do nível de educação da mãe, obtida a partir da classificação do } \\
\text { International Standard of Education - ISED (Original do PISA - MISCED). }\end{array}$ \\
\hline
\end{tabular}

Tabela 1 - Estatísticas descritivas das variáveis utilizadas

\begin{tabular}{|l|c|c|c|c|}
\hline Variável & Média & Desvio Padrão & Mín. & Máx. \\
\hline Proficiência & 402,86 & 89,07 & 22,27 & 738,66 \\
\hline Posse de bens & 0 & 1 & $-3,38$ & 4,41 \\
\hline Diálogo familiar & 0 & 1 & $-2,35$ & 3,34 \\
\hline Status ocupacional & 0 & 1 & $-1,50$ & 2,92 \\
\hline Recursos educacionais familiares & 0 & 1 & $-3,54$ & 1,61 \\
\hline Baixa posse - baixo recurso & 0,24 & 0,43 & 0 & 1 \\
\hline Alta posse - alto recurso & 0,19 & 0,39 & 0 & 1 \\
\hline Alta posse - baixo recurso & 0,14 & 0,35 & 0 & 1 \\
\hline Baixa posse - alto recurso & 0,15 & 0,36 & 0 & 1 \\
\hline Posse de bens culturais & 0 & 1 & $-1,33$ & 1,66 \\
\hline Nível de escolaridade da mãe & 0 & 1 & $-2,00$ & 2,00 \\
\hline
\end{tabular}


capital social. Um dos objetivos deste trabalho é medir o efeito da mobilização da rede de apoio familiar sobre o desempenho escolar. Nossa hipótese é que determinados arranjos de capitais possuem efeitos diferenciados, uma vez que indicam o grau de mobilização da rede de apoio familiar.

Para isso, utilizamos a seguinte estratégia de análise: a) análise de conglomerados (clusters analysis) cujo objetivo é agrupar objetos segundo determinadas características, formando grupos ou conglomerados homogêneos; e b) inclusão, no modelo de regressão linear, de dummies relativas ao pertencimento em cada um dos conglomerados obtidos.

As variáveis incluídas na análise de conglomerados (K-means clusters) foram: posse de bens e recursos educacionais familiares, medidas de capital econômico e de capital social, respectivamente. A análise envolveu a criação de cinco conglomerados cujos centroides foram definidos a priori com base na literatura e de modo que caracterizem os seguintes arranjos:

- Médio nível de posse de bens e médio nível de recursos educacionais familiar;

- Alto nível de posse de bens e alto nível de recursos educacionais familiar;

- Baixo nível de posse de bens e baixo nível de recursos educacionais familiar;

- Alto nível de posse de bens e baixo nível de recursos educacionais familiar;

- Baixo nível de posse de bens e alto nível de recursos educacionais familiar.

Em uma regressão linear, o coeficiente estimado associado a uma variável permite mensurar o seu efeito médio para um determinado conjunto dos dados. A inclusão no modelo de regressão linear das dummies relativas ao pertencimento de cada conglomerado permite avaliar como o impacto na proficiência em leitura se diferencia de acordo com as características que definem um determinado conglomerado. Um exemplo poderá ilustrar melhor o argumento: o desempenho em leitura entre alunos com alta posse de bens pode ser diferente quando transitamos por níveis de recursos educacionais familiares distintos.
Figura 1 - Caracterização dos conglomerados utilizados na análise

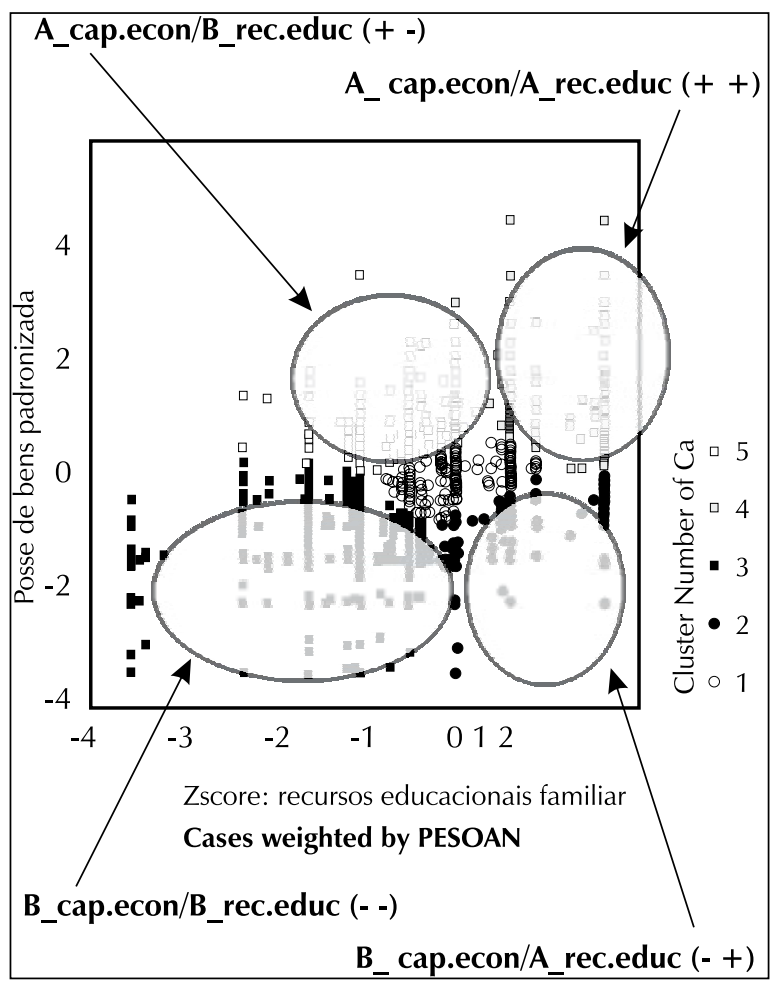

Fonte: PISA 2000

\section{Resultados}

Inicialmente apresentaremos os resultados do modelo sem a inclusão das dummies de pertencimento aos aglomerados. Em consonância com os resultados encontrados pela literatura educacional, a tabela 2 mostra que os diferentes tipos de capitais estão correlacionados com o desempenho em leitura. Com relação à variável "Posse de bens", constatamos que, em média, os alunos com nível mais elevado apresentam acréscimo, no desempenho em leitura, de aproximadamente 9 pontos.

As variáveis "Diálogo familiar", "Status ocupacional" e "Recursos educacionais familiares" apresentam efeito positivo na melhoria do desempenho dos alunos brasileiros em leitura. Em relação à última variável, o aumento de uma unidade corresponde a uma elevação, em média, de aproximadamente 11 pontos na proficiência. A variável "Diálogo familiar" segue o mesmo padrão de associação das demais. Cabe ressaltar 
que esta variável foi a menos afetada pela inclusão das diversas variáveis, indicando que o diálogo familiar é fator importante para o desempenho escolar e todos os grupos sociais se beneficiam dele.

A variável "Nível de escolaridade da mãe" apresenta associação positiva de cerca de 8 pontos com o desempenho em leitura. O nível de escolaridade do pai foi considerado ao longo das análises realizadas, entretanto no modelo final o coeficiente associado a esta variável não se mostrou estatisticamente significativo.

Tabela 2 - Modelo para a relação entre desempenho em Leitura e tipos de capitais

\begin{tabular}{|c|c|c|}
\hline Tipo de capital & Variáveis & Modelo * $^{*}$ \\
\hline \multirow{2}{*}{ Econômico } & Constante & 409,42 \\
\cline { 2 - 3 } Social & Posse de bens & 9,0 \\
\hline \multirow{2}{*}{ Cultural } & Diálogo familiar & 9,0 \\
\cline { 2 - 3 } & $\begin{array}{c}\text { Status ocupa- } \\
\text { cional }\end{array}$ & 9,0 \\
\cline { 2 - 3 } & $\begin{array}{c}\text { Recursos educa- } \\
\text { cionais familiares }\end{array}$ & 11,0 \\
\cline { 2 - 3 } & $\begin{array}{c}\text { Nível de escola- } \\
\text { ridade da mãe }\end{array}$ & 8,0 \\
\cline { 2 - 3 } & $\begin{array}{c}\text { Posse de bens } \\
\text { culturais }\end{array}$ & 3,0 \\
\hline \multirow{2}{*}{$\mathbf{R}^{\mathbf{2}}$} & \multicolumn{2}{|c|}{0,162} \\
\hline
\end{tabular}

* todos os coeficientes são significativos a $95 \%$

Passaremos agora para a discussão dos resultados do modelo com a inclusão das dummies de pertencimento ao conglomerado. Como podemos ver na tabela 3, o comportamento das variáveis foi semelhante ao encontrado no modelo anterior.

Os efeitos da inclusão das dummies neste modelo, mantidas todas as outras variáveis constantes, são os seguintes:

- Alunos com recursos educacionais familiares um desvio padrão abaixo da média perdem, em média, cerca de 10 pontos na escala de proficiência do PISA;

- Alunos com recursos educacionais familiares um desvio padrão abaixo da média e posse de bens abaixo da média não perdem nada além da perda de aproximadamente 15 pontos, devido à baixa posse de bens;
- Alunos com recursos educacionais familiares um desvio padrão abaixo da média e alta posse de bens perdem em torno de 11 pontos, por conta de pertencerem a esse conglomerado, perdem mais 10 pontos aproximadamente por conta de não terem recursos educacionais familiares, a despeito de sua posse bens, ainda que ganhem cerca de 15 pontos por conta da alta posse de bens.

Tabela 3 - Modelo para a relação entre desempenho em Leitura e dummies relativas ao pertencimento dos conglomerados

\begin{tabular}{|c|c|c|}
\hline Tipo de capital & Variáveis & Modelo $2^{*}$ \\
\hline \multirow{2}{*}{ Econômico } & Constante & 407,15 \\
\hline & Posse de bens & 15 \\
\hline \multirow{4}{*}{ Social } & Diálogo familiar & 9,0 \\
\hline & $\begin{array}{l}\text { Status ocupa- } \\
\text { cional }\end{array}$ & 9,0 \\
\hline & $\begin{array}{l}\text { Recursos educa- } \\
\text { cionais familiares }\end{array}$ & 10,0 \\
\hline & $\begin{array}{c}\text { Baixa posse } \\
\text { de bens e alto } \\
\text { recurso educa- } \\
\text { cional familiar } \\
(-+)\end{array}$ & 9,0 \\
\hline \multirow{3}{*}{ Social } & $\begin{array}{l}\text { Baixa posse de } \\
\text { bens e baixo } \\
\text { recurso educa- } \\
\text { cional familiar } \\
\left(-{ }^{-}\right)\end{array}$ & 10,0 \\
\hline & $\begin{array}{l}\text { Alta posse de } \\
\text { bens e alto } \\
\text { recurso educa- } \\
\text { cional familiar } \\
\quad(++)\end{array}$ & 0,7 \\
\hline & $\begin{array}{l}\text { Alta posse de } \\
\text { bens e baixo } \\
\text { recurso educa- } \\
\text { cional familiar } \\
(+-)\end{array}$ & $-11,0$ \\
\hline \multirow{2}{*}{ Cultural } & $\begin{array}{l}\text { Nível de escola- } \\
\text { ridade da mãe }\end{array}$ & 8,0 \\
\hline & $\begin{array}{c}\text { Posse de bens } \\
\text { culturais }\end{array}$ & 3,0 \\
\hline $\mathrm{R}^{2}$ & & 0,166 \\
\hline
\end{tabular}

* todos os coeficientes são significativos a $95 \%$. 
A figura 2 mostra o valor médio da proficiência estimada pelo modelo 1 e pelo modelo 2 levando em consideração as variáveis "Posse de bens" e "Recursos educacionais familiares”, mantendo as outras variáveis constantes.

Figura 2 - Média e Efeito dos Recursos Educacionais Familiares em diferentes grupos econômicos

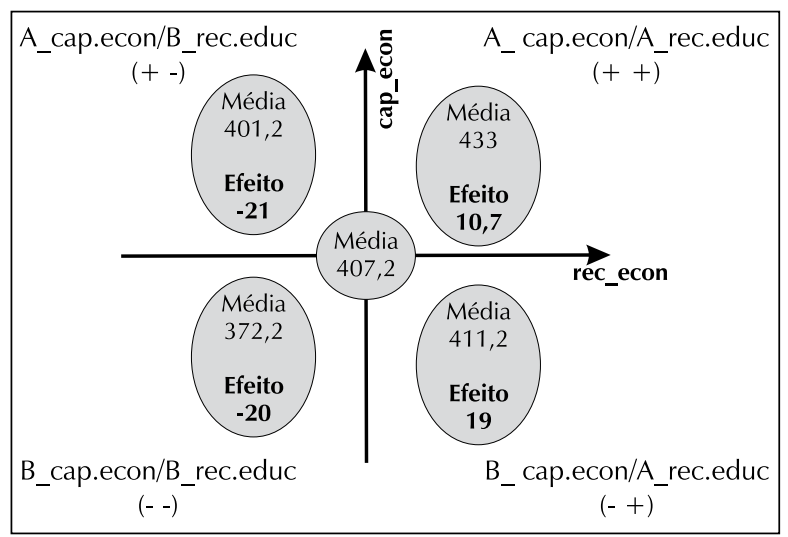

Fonte: PISA 2000.

\section{Considerações finais}

Com base neste estudo, podemos destacar dois achados sociologicamente significativos relacionados com o conceito de capital social familiar.

Em primeiro lugar, nossos resultados apontam o "Diálogo familiar" como um fator com grande poder explicativo do desempenho escolar, uma vez que, em média, os estudantes pertencentes a todos os grupos sociais se beneficiam de seu efeito positivo. Daí a importância do diálogo familiar como indicador do papel do capital social.

Em segundo lugar, a inclusão das variáveis "Posse de bens" e "Recursos educacionais familiares" na análise de conglomerados permitiu investigar como arranjos estruturais diferenciados de capital econômico e social se relacionam com o desempenho escolar, complementando análises tipicamente baseadas nos efeitos do volume dos capitais.

Entre esses arranjos, os efeitos mais ilustrativos da potencialidade desse tipo de análise para a compreensão da mobilização de capital social baseado na família são os relacionados com "Alta posse de bens/Baixa posse de recursos educacionais familiares" e "Baixa posse de bens/Alta posse de recursos educacionais familiares".

O primeiro arranjo permite concluir que, apesar de as famílias possuírem alto capital econômico, este não é disponibilizado na forma de recursos educacionais para apoiar a escolarização dos filhos. Nesse grupo, os estudantes têm, em média, desempenho abaixo da média geral (401 e 407, respectivamente), indicando baixa mobilização de capital social familiar.

Em contraste, o alto grau de mobilização de capital social identificado pelo segundo arranjo mostra que, a despeito de as famílias deterem baixo capital econômico, disponibilizam para seus filhos recursos educacionais que redundam em um desempenho acima da média geral (411 e 407, respectivamente).

Os achados deste estudo corroboram a ideia de que, em países com características socioeconômicas semelhantes às do Brasil, o capital social baseado na família é relevante para a vida e a aprendizagem escolar dos filhos.

\section{Referências bibliográficas}

BOURDIEU, Pierre. O capital social: notas provisórias. In: NOGUEIRA, Maria Alice; CATANI, Afrânio (Orgs.) Escritos de educação. Petrópolis: Vozes, 1980. p. 65-69 (3. ed., 2001).

The forms of capital. In: RICHARDSON, J. G. (Ed.)

Handbook of Theory and Research for the Sociology of Education. New York: Greenwood Press, 1985. p. 241-258.

. O poder simbólico. Rio de Janeiro: Bertrand Brasil, 1989.

Razões práticas: sobre a teoria da ação. Campinas:

Papirus, 1997.

BOURDIEU, Pierre. Os três estados do capital cultural. In: NOGUEIRA, Maria Alice; CATANI, Afrânio (Org.). Escritos de educação. Petrópolis: Vozes, 1979. p. $73-79$ (3. ed., 2001).

BOURDIEU, Pierre; PASSERON, Jean Claude. Les héritiers, les étudiants et la culture. Paris: Ed. de Minuit, 1964.

La reproduction: éléments pour une théorie du système d'enseignement. Paris: Ed. de Minuit, 1970.

COLEMAN, James S. Social capital in the creation of human capital. American Journal of Sociology, v. 94, p. 95-120, 1988. 
Equality of Educational Opportunity. Washington: Office of Education, U.S., 1966.

HOGAN, David; OWEN, David. Social capital, active citizenship and political equality in Australia. In: WINTER, Ian (Ed.) Social capital and public policy in Australia. Melbourne: Australia Institute of Family Studies, 2000. p. 74-104.

KLIKSBERG, Bernardo. El rol del capital y de la cultura en el proceso de desarrollo. In: KLIKSBERG, Bernardo; TOMASSINI, Luciano (Org.). Capital social y cultura: claves estratégicas para el desarrollo. Buenos Aires: Fondo de Cultura Económica de Argentina, 2000. p. 19-58.

NOGUEIRA, Cláudio M. Martins; NOGUEIRA, Maria Alice. A sociologia da educação de Pierre Bourdieu: limites e contribuições. Educação \& Sociedade, Campinas, n. 78, p. 15-36, abr. 2002.

ORTIZ, Renato (Org.). Pierre Bourdieu. Sociologia. São Paulo: Ática, 1983.

PORTES, Alejandro. Social capital: its origins and applications in modern sociology. Annual Review Sociology, n. 24, p. 1-24, 1998.

PUTNAM, Robert. D. Making democracy work: civic traditions in modern Italy. Princeton: Princeton University Press, 1993.

WINTER, I. Towards a theorized understanding of family life and social capital. Working paper (Australia Institute of Family Studies), n. 21, p. 1-18, abr. 2000.

\section{Apêndice}

Descrição das variáveis utilizadas na análise

- Variável dependente:

- Proficiência em leitura - um teste de leitura foi administrado para alunos de 15 anos e estimada uma proficiência a partir do método Weighted Maximum Likelihood (PISA 2000/Technical Report, 2001). Para a amostra do PISA 2000 essa variável foi padronizada com a seguinte métrica: média $=500, \mathrm{SD}=100$. Original do PISA $=$ WLEREAD.

- Variáveis independentes:

- Posse de bens - indicador de posse de bens construído pelo PISA(WEALTH) obtido a partir dos seguintes itens do questionário dos alunos:

- Disponibilidade de máquina de lavar pratos em casa
- Disponibilidade de quarto próprio

- Disponibilidade de softwares educacionais

- Disponibilidade de acesso à internet

- Número de telefones celulares

- Número de televisores

- Número de computadores

- Número de carros

- Número de banheiros

- Diálogo familiar - indicador de diálogo familiar construído a partir dos seguintes itens do questionário do aluno sobre a frequência com que seus pais:

- Conversam sobre assuntos políticos ou sociais com você

- Conversam sobre livros, filmes ou programas de televisão com você

- Ouvem música clássica com você

- Almoçam ou jantam com você

- Passam o tempo "batendo papo" com você

A frequência foi medida a partir de cinco categorias de resposta: nunca ou quase nunca; poucas vezes por ano; cerca de uma vez por mês; várias vezes por mês e várias vezes por semana. Obtido com base na Teoria de Resposta ao Item Não Paramétrica (forma generalizada da escala de Mokeen para itens dicotômicos Molenaar, 1997). Os valores de fidedignidade foram: alpha $=\mathrm{XX}$ e rho $=$ YY.

- Status ocupacional - indicador construído pelo PISA (ISEI - International Socio Economic Index), derivado da classificação das respostas dos alunos sobre a ocupação do pai e da mãe dentro do International Standard Classification of Occupations. Se o estudante forneceu respostas tanto para o pai quanto para mãe, o valor do ISEI é o maior deles.

- Recursos educacionais familiares - Indicador da disponibilidade e da quantidade de recursos educacionais em casa de construído pelo PISA(HEDRES). Medida sobre a obtida a partir das respostas dos alunos aos seguintes itens:

- na sua casa você possui um dicionário?

- um lugar calmo para estudar?

- uma mesa para estudar?

- livros-textos?

- quantas calculadoras existem na sua casa?

- Posse de bens culturais - Medida sobre a posse de bens 
relacionados à cultura clássica (CULTPOSS), obtida a partir das respostas dos alunos ao questionário aos seguintes itens:

- na sua casa você tem livros de literatura clássica?

- livros de poesia?

- obras de arte?

- Nível educacional da mãe - Indica o nível mais alto de educação da mãe dos alunos. Obtida a partir da classificação do International Standard of Education - ISED (Original do PISA - MISCED).

- não estudou

- completou o primeiro segmento do ensino fundamental

- completou o segundo segmento do ensino fundamental

- completou o ensino médio

- completou o ensino superior

ALICIA BONAMINO é doutora em educação e professora da Pontifícia Universidade Católica do Rio de Janeiro (PUCRio). Desenvolve a pesquisa "Aprendizagem de leitura nos anos iniciais do ensino fundamental e sua relação com as práticas dos professores em sala de aula”. Suas publicações mais importantes foram Bonamino, A. M. C.; Alves, Fátima. Investigação de fatores associados à eficácia escolar no Brasil e em Portugal a partir dos dados do PISA 2000 [In: Souza, Donaldo Bello de; Martinez, Silvia Alicia. (Org.). Educação comparada: rotas de além-mar. São Paulo: Xamã, 2009, v. 1, p. 1-524]; A Constituição Federal de 1988 e a realidade educacional após 21 anos de sua promulgação [In: Versini, Maria Helena; Melhem Santos, Nubia (Org.). A voz e a letra do cidadão. Rio de Janeiro: Janá/Museu da República, 2009, v. 1, p. 7-131]; Franco, Creso; Alves, Fátima; Bonamino, A. M. C. Qualidade do ensino fundamental: políticas, suas possibilidades, seus limites [Educação \& Sociedade (impresso), v. 28, p. 989-1014, 2007].E-mail: alicia@puc-rio.br

SIBELE CAZELLI é doutora em educação e atua na Coordenação de Educação do Museu de Astronomia e Ciências Afins (MAST). Desenvolve, em parceria com a Faculdade de Educação da PUC-Rio, as pesquisas "Juventude e mídia: contextos escolares e sociais" e "Mais tempo ao tempo: o estudo de conceitos temporais em diferentes áreas de conhecimento do ensino fundamental".
Suas últimas publicações foram: Jovens nos museus: quem são, aonde vão e com quem visitam? [In: Dalben, A.; Diniz, J.; Leal, L.; Santos, L. (Org.). Convergências e tensões no campo da formação e do trabalho docente. Belo Horizonte: Autêntica, 2010, 693p. p. 402-425; Didática e prática de ensino]; Cazelli, S.; Costa, A. F.; Mahomed, C. O que precisa ter um futuro professor em seu curso de formação para vir a ser um profissional de educação em museus? (In: Encontro Articulando a Universidade e a Escola Básica no Leste Fluminense: Ações, Reflexões e Alternativas Futuras, 2., 2009, Rio de Janeiro. Anais... Rio de Janeiro: Faculdade de Formação de Professores, UERJ, 2009. 1 CD-ROM. ISSN 2175-6937); Köptcke, L. S.; Cazelli, S.; Lima, J. M. de. Museus e seus visitantes (Brasília: Gráfica e Editora Brasil, 2008.76p.).E-mail: sibele@mast.br

FÁTIMA ALVES é doutora em educação e professora da Pontifícia Universidade Católica do Rio de Janeiro (PUC-Rio). Desenvolve a pesquisa "Cidade, escola e família: estudos sobre desigualdades de oportunidades educacionais a partir de dados longitudinais". Suas últimas publicações foram Mapeamento das políticas de escolha de diretores da escola e de avaliação na Rede Pública das capitais brasileiras (Revista Brasileira de Estudos Pedagógicos, v. 90, p. 71-86, 2009); Alves, F.; Franco, C.; Queiroz, L. C. R. Segregación urbana y rezago escolar en Río de Janeiro (Revista de la CEPAL, v. 94, p. 133-148, 2008); Políticas educacionais e desempenho escolar nas capitais brasileiras (Cadernos de Pesquisa, Fundação Carlos Chagas, v. 38, p. 413-440, 2008). E-mail: fcalves@puc-rio.br

CRESO FRANCO é doutor em educação e professor da Pontifícia Universidade Católica do Rio de Janeiro (PUC-Rio). Desenvolve a pesquisa "Estudo longitudinal da Geração Escolar 2005 - GERES”. Suas publicações mais importantes foram: Franco, Creso; Brooke, Nigel; Alves, Fátima. Estudo longitudinal sobre qualidade e equidade no ensino fundamental brasileiro: GERES 2005 (Ensaio: aval.pol.públ.Educ., v. 16, n. 61, p. 625-637, dez. 2008); Franco, Creso; Alves, Fátima; Bonamino, A. M. C. Qualidade do ensino fundamental: políticas, suas possibilidades, seus limites [Educação \& Sociedade (impresso), v. 28, n. 100, p. 989-1014, out. 2007].E-mail: creso.franco@daframotos.com.br

Recebido em julho de 2010 Aprovado em julho de 2010 
Alicia Bonamino, Sibele Cazelli, Fátima Alves e Creso Franco

Os efeitos das diferentes formas de capital no desempenho escolar: um estudo à luz de Bourdieu e de Coleman

Bourdieu e Coleman introduziram o conceito de capital em bases teóricas distintas para falar das vantagens culturais e sociais mobilizadas pelos indivíduos e que geralmente os conduzem a um nível socioeconômico mais elevado. O presente estudo tem como objetivo avaliar os méritos relativos dessas abordagens sociológicas, explorar o potencial explicativo do capital econômico, social e cultural na análise do desempenho educacional e analisar os efeitos das diferentes formas de capital e de sua mobilização familiar sobre o desempenho em leitura dos estudantes brasileiros participantes do Programa Internacional de Avaliação de Estudantes (PISA), realizado em 2000. Os dados foram analisados por meio de modelos de regressão linear e de análise de conglomerados. Os resultados apontam que as variáveis relacionadas aos diferentes tipos de capital possuem efeitos significativos no desempenho escolar, particularmente o capital social e sua mobilização pela rede de apoio familiar.

Palavras-chave: capital social baseado na família; desempenho escolar; avaliação educacional; Programa Internacional de Avaliação de Alunos (PISA)

The effects of the different forms of capital on school performance: a study illuminated by Bourdieu and

\section{Coleman}

Bourdieu and Coleman introduced the concept of capital on distinct theoretical bases to speak of the cultural and social advantages mobilized by individuals and which generally lead them to a higher socioeconomic level. The aim of the present study is to evaluate the relative merits of these sociological approaches, to explore the explanatory potential of economic, social and cultural capital in the analysis of educational performance, and to analyze the effects of the different forms of capital and their familial mobilization on the reading performance of Brazilian students who participated in the Programme for International Student Assessment (PISA) held in 2000. The data was analyzed using models of linear regression and the analysis of conglomerates. The results suggest that the variables related to the different types of capital have significant effects on school performance, especially social capital 
and its mobilization by the network of family support.

Key words: social capital based on the family; school performance; educational evaluation; Programme for International Student Assessment (PISA)

Los efectos de las diferentes formas de capital en el desempeño escolar: un estudio con base en Bourdieu y

\section{Coleman}

Bourdieu y Coleman introdujeran el concepto de capital en bases teóricas distintas para hablar de las ventajas culturales y sociales movilizadas por los individuos y que generalmente los conducen a un nivel socioeconómico más elevado. El presente estudio tiene como objetivo evaluar los méritos relativos de estos abordajes sociológicos; explorar el potencial explicativo del capital económico, social y cultural en el análisis del desempeño educacional; y analizar los efectos de las diferentes formas de capital y de su movilización familiar sobre el desempeño en lectura de los estudiantes brasileños participantes del Programa Internacional de Evaluación de Estudiantes (PISA 2000). Los datos fueron analizados por medio de modelos de regresión lineal y de análisis de conglomerados. Los resultados apuntan que las variables relacionadas a los diferentes tipos de capital tienen efectos significativos en el desempeño escolar, particularmente el capital social y su movilización por la red de apoyo familiar.

Palabras clave: capital social fundamentado en la familia; desempeño escolar; evaluación de la educación; Programa Internacional de Evaluación de Alumnos (PISA) 